\title{
Nanotechnology and Global Applications: Bench to Community
}

\author{
Dr. Ashok Chakraborty (Corresponding Author) \\ Professor, Sacredheart University, CT, USA. Email: ashok.chakraborty@yale.edu
}

Dr. Smita Guha

Associate Professor, St. John's University, NY, USA

Dr. Prabir Patra

Chair and Professor, University of Bridgeport, CT, USA

Running title: Nano Technology from Bench to Community

Received: Sep. 1, 2020 Accepted: Sep. 20, 2020

doi:10.5296/jbls.v11i2.17617 URL: https://doi.org/10.5296/jbls.v11i2.17617

\begin{abstract}
Advances in nanotechnology has become enormously promising in the field of health science, in developing many medical equipment. The possible effects of novel nanomedical technology significantly improve the diagnosis and therapeutic aspects of many diseases. Nanomaterials are being applied in operation, disease diagnosis as well as therapy, molecular imaging, implant technology, tissue engineering, as well as a device for efficient drug delivery, protein and gene release. In this review we discussed the utility of nanoscience in health issues, and the knowledge from there how can be disseminated to the educators and parents for expanding STEM (Science, Technology, Engineering and Math) programs.
\end{abstract}

Keywords: nanotechnology, health science, community, school curriculum

\section{Introduction}

Nanotechnology is the science where the nanomaterials, generally 1-100 nanometers size, are 
exploited in designing, creation, and application of functional materials and/or devices for modern science and technology used in health science, environmental science, energy and electronics, etc. (Bayda et. al. 2019) The properties of many conventional materials change when formed from nanoparticles (UnderstandingNano.com: nanoparticles 2019). This is typically because nanoparticles have a greater surface area per weight than larger particles which causes them to be more reactive to some other molecules (Hulla et. al. 2015).

Nanoparticles are used, or being evaluated for use, in many fields, like: In Environmental Science, e.g. Photocatalytic copper tungsten oxide nanoparticles for break down of oil into biodegradable compounds; Gold nanoparticles embedded in a porous manganese oxide break down volatile organic pollutants in air; Iron nanoparticles clean up carbon tetrachloride pollution in ground water; Iron oxide nanoparticles clean arsenic from water wells; etc. (UnderstandingNano.com: environmental-nanotechnology, 2019).

In Electronics and Energy, Nanotetrapods studded with nanoparticles of carbon are being used as a low cost electrodes for fuel cells. This electrode may be able to replace the expensive platinum needed for fuel cell catalysts. Silver nanoparticle ink form the conductive lines needed in circuit boards. Combining gold nanoparticles with organic molecules creates a transistor known as a NOMFET (Nanoparticle Organic Memory Field-Effect Transistor). This transistor is unusual in that it can function in a way similar to synapses in the nervous system. A catalyst using platinum-cobalt nanoparticles is being developed for fuel cells that produces twelve times more catalytic activity than pure platinum. The "solar steam device" is intended to be used in the areas of developing countries without electricity (Scientific World Info. 2020).

Most importantly, the application of nanotechnology in medicine is enormous. Nanoparticles can be engineered to incorporate a wide variety of chemotherapeutic or diagnostic agents, creating flexibility in their design that is not possible with other types of selective drug delivery systems (Bharali and Mousa 2010). Here we will be discussing the information in nanoscience as well as nanotechnology in the field of health science in terms of early diagnosis of the disease, it's treatment, and also the development of equipments and medical devices to be used in medical science. (Lee and Wong 2011).

Therefore, a comprehensive national skill should be developed to form an appropriate work-force which in combination with consumer acceptance could be a major factor for the success of any nanotechnological approach.

\section{A) In Medicine:}

A-1) Drug delivery: Nanotechnology can help an efficient targeted drug delivery to the diseased lesions. Engineering of the Nanoparticles may allow to incorporate different kinds of chemotherapeutics or diagnostic agents, which is not possible in other kinds of drug delivery systems (Bharali and Mousa 2010; Misra et. al. 2010) has shown that drug-loaded nanoparticles can selectively target tumor cells without causing any damage to the healthy cells.

Liposomes as a carrier have some unique advantages besides targeting, like capability to 
block the degradation of drugs and their any side effects (Knight 1981). However, low efficiency of liposomes-mediated encapsulation, seepage of water-soluble drugs, as well as weak stability of encapsulated drug complex, limits their use. Nanoparticles like PLGA-PEG co-polymers, however, increase the half-life of circulating cisplatine (Avgoustakis, et al. 2002).

A-2) Biosensors that can identify the process mechanism, are made up of biological material those are responsible for sampling and transmitting the chemical senses. (Vo-Dinh, et al. 2000; 2001; Thévenot et al. 2001; Mohanty 2001). Concerning the biological specificity the biosensors could be developed like, Antibody/antigen based, Enzymes based (Alcala et al. 2002); Nucleic acids based (Kwakye and Baeumner 2003); cellular structures/cells based (Kitova, et al. 2002; Köhler, et. al 2000; Dubey and Upadhyay 2001; Degrassi et. al. 2002; Hansen and Sorrensen 2001; Mitchell and Gu 2003).

Nanobarcodes, metallic nanobeads, quantum dots, magnetic beads, silica nanoparticles, as well as carbon nanotubes are mostly used as a Biosensors. This is one of the example of many implementation of nanoscience in the field of disease biology, its diagnostics and in therapeutics, too.

A-3) Gene/Antisense therapy: Gene therapy means the correction of the defective gene responsible for the onset of the disease or delivery of the repaired gene. Antisense strategy modulates the disease-related gene transcription in vivo, therefore it is also considered as a valid therapy to treat any genetic disorders. These include any carcinoma (Cunningham et. al. 2001; Rudin, et al. 2001; Morris et al. 2002; Mani, et al. 2002), including non-Hodgkin's lymphoma (Waters et al. 2000; Gewirtz, 1999), acute myeloid or lymphoblastic leukemia (Marcucci, et al. 2003) as well as chronic myelogenous leukemia (CML) (Luger, et al. 2002). However, the antisense oligonucleotides, due to having low intracellular penetrating ability and strong nuclease activity in vivo, have restricted use as a therapeutic regiment (Loke, et al. 1989; Yakubov et. al. 1989).

Engineered nanoparticles can be used for delivery of the correct gene, or antisense RNA or siRNA for the gene-related diseases. The advantages of using polymer-DNA complex vectors, in which polymer of $25-300 \mathrm{~nm}$ in diameter wrap around the DNA to protect it and improves the cell transfection efficiency.

A-4) Administration of DNA Vaccines: Nanoparticles if can be bound up with inactive virus then can be used as an alternative to injectable vaccines to increase the immune response. Scientists are investigating the efficacy of nanotechnology-based skin patch against West Nile Virus and Chikungunya virus (Prow et al. 2010).

Genetic immunization with DNA vaccines (Ulmer et. al. 1996; Dubensky et. al. 2000). have many advantages over conventional vaccines because of their increased stability, lack of infection possibilities associated with attenuated viral vaccines, the capacity of packaging multiple antigens in the same plasmid, as well as their ability to express cellular immune responses humoral as well as cellular, both. 


\section{B) In Cell Biology}

Nanotechnology can be utilized to create an artificial cells, tissues as well as organs. Cell therapy for diabetes, liver disease, kidney failure is being done by implantation of encapsulated normal and active cells or genetically engineered cells. Artificial cells can also be used for drug delivery (Orive et al. 2003; Chang 2003).

\section{C) Nanotechnology: Bench to Community}

Nanomaterials are being consumed in our daily lives in different ways, often without the consumer knowledge. A strong social supports and consumer awareness can further develop the vast use of nanotechnology.

Our mission as educators are to instill and arouse students' curiosity in learning the future frontier science. The knowledge of Nanoscience could be integrated in the school science curricula as early as preschool through higher education. Some of the topics that could be included are origins of nanotechnology, associated challenges about nanotechnology for educational implementation, examination of currently available school activities, types of current product applications, about the ethical issues related to nanotechnology, recommendations for educational policy along with teaching approaches and practical implications of nanotechnology.

\section{C-1) In Secondary Education}

Due to the expansion of nanoscience, there is now necessity to integrate the concepts of nanotechnology in the school curriculum that are both relevant and meaningful to the students (Ghattas and Caryer 2012).

Few such key categories that are important in high school science education are: the origins of nanotechnology; their implications; challenges and ethical issues integrating educational curriculum.

In a study by Pelleg (2011) reported on a program that aimed to expose high school students to nanotechnology. They developed a series of nanotechnology modules for an introductory engineering elective course in an urban public magnet high school. The fellows in the program implemented the unit in two classrooms during the 2009-2010 school year. The unit introduced students to some of the key concepts of nanotechnology. Among those included the relative magnitude of a nanometer, surface area to volume ratio, and nanoscale characterization. Before introducing this unit, the students only had perceptions about nanotechnology that were shaped by popular culture, movies, and video games. However, after learning about this unit, the post-test results indicated a shift in the students' conceptions of nanotechnology. Therefore, this unit could be used as a model for inserting a nanotechnology focused unit into a high school classroom. This unit meets core curriculum standards as required by state governments.

Similarly, in another study by Lin (2015) a human resources development program was implemented as one of the nanotechnology incubation projects in Taiwan for the sixth grade school children in four schools. The concepts in nanotechnology included 'Nanophenomena 
in the natural world'; 'Nanomaterials and their scaling effects'; and 'Definition, characteristics, and applications of nanotechnology.' The result indicated positive change related to nanotechnology concepts for more than $30 \%$ of students.

\section{C-2) In Developing Countries}

Several developing countries are very active now-a-days in promoting nanotechnology-related approaches to build up their economical growth as well as in health science area (Court et. al. 2004). In India, Panacea Biotech (New Delhi, India: http://www.panacea-biotec.com/products/products.htm) is using muco-adhesive nanoparticles in conducting a novel drug delivery research. Dabur Research Foundation (Ghaziabad, India) is conducting a Phase-1 clinical trials of anti-cancer drug paclitaxel delivery using nanoparticles (Bapsy et al. 2004). The number of patent applications from China on nanotechnology ranks third in the world, where United States and Japan are the first two (NBIC 2018). In Brazil, the projected budget in 2004-2007 for the development of nanoscience is about $\$ 25$ millions. Three institutes, and many networks, including more than 300 scientists are working there on nanotechnology (Salamanca-Buentello et. al. 2005).

The South African Nanotechnology Initiative (SANI. 2014) is a national organization of academic researchers working on the development of nanophase catalysts, nanowires, nanofilters and nanotubes. Other developing countries, such as Thailand, Philippines, Chile, Argentina, and Mexico, are also pursuing nanotechnology-based science (Court et. al. (2004).

\section{C-3) Public acceptance}

Unfortunately nanoscience, in developing countries, raises many ethical issues, like to accept genetically modified foods. Introducing health products created using nanotechnology require an experienced professional in that area, but nay be lacking in a developing countries (The Royal Society and Royal Academy of Engineering Nanoscience and Nanotechnologies: Opportunities and Uncertainties, 2004). Even the developed countries sometimes face many challenges like ethical, environmental and equities that are obstructing the scientific advances of nanotechnology. In fact, acceptance of nanotechnology-based products, depends on how it is being used as end products.

\section{Conclusion}

In conclusion, the expectations of nanoscience in the area of health and medicine are though high, however, the safety of nanomedicine(s) should be explained well. Further, concurrent application of nanotechnology in other fields, like diagnostics, development of molecular research tools should also be explored.

\section{Acknowledgement}

We acknowledge all our colleagues for their help during the preparation of the manuscript by providing all the relevant information. We are also tankful to the Departmental secretary (St. John's Univ) for editing the manuscript.

\section{Conflict of Interest}

All the Authors have no conflict of Interest in this paper. 


\section{References}

Alcala, P., Ferrer-Miralles, N., Feliu, J. X., \& Villaverde, A. (2002). Co-activation of antibody-responsive, enzymatic sensors by a recombinant scFv antibody fragment produced in E. coli Biotechnol. Lett., 24(19), 1543-1551. https://doi.org/10.1023/A:1020371220100

Avgoustakis, K., Beletsi, A., Panagi, Z., Klepetsanis, P., Karydas, A. G., \& Ithakissios (2002). PLGA-mPEG nanoparticles of cisplatin: in vitro nanoparticle degradation, in vitro drug release and in vivo drug residence in blood properties. J. Control Release, 79, 123-135. https://doi.org/10.1016/S0168-3659(01)00530-2

Bapsy, P. P., Raghunadharao, D., Majumdar, A., Ganguly, S., Roy, A. et al. (2004). DO/NDR/02a novel polymeric nanoparticle paclitaxel: Results of a phase I dose escalation study. J Clin Oncol 22 (14S), 2026. https://doi.org/10.1200/jco.2004.22.90140.2026

Bayda, S., Adeel, M., Tuccinardi, T., Cordani, M., \& Rizzolio, F. (2019). The History of Nanoscience and Nanotechnology: From Chemical-Physical Applications to Nanomedicine. Molecules, 25(1), 112. https://doi.org/10.3390/molecules25010112

Bharali, D. J.., \& Mousa, S. A. (2010). Emerging nanomedicines for early cancer detection and improved treatment: Current perspective and future promise. Pharmacology \& Therapeutics. 128(2), 324-335. https://doi.org/10.1016/j.pharmthera.2010.07.007

Chang, T. M. S. (2003). Artificial Cells for Replacement of Metabolic Organ Functions. Artificial Cells, Blood Substitutes, and Biotechnology, 31(2), 151-161. https://doi.org/10.1081/BIO-120020173

Court, E., Daar, A. S., Martin, E., Acharya, T., \& Singer, P. A. (2004). Will Prince Charles et al diminish the opportunities of developing countries in nanotechnology? Sci Dev Net., 24/11/2010. http://www. nanotechweb.org/articles/society/3/1/1/1.

Cunningham, C. C., Holmlund, J. T., Geary, R. S., Kwoh, T. J., Dorr, A., Johnston, J. F., ... Nemunaitis, J. (2001). A Phase I trial of H-ras antisense oligonucleotide ISIS 2503 administered as a continuous intravenous infusion in patients with advanced carcinoma. Cancer, 92, 1265-1271.

https://doi.org/10.1002/1097-0142(20010901)92:5<1265::AID-CNCR1447>3.0.CO;2-5

Degrassi. G., Aguilar, C., Bosco, M., Zahariev, S., Pongor, S., \& Venturi, V. (2002). Plant Growth-Promoting Pseudomonas putida WCS358 Produces and Secretes Four Cyclic Dipeptides: Cross-Talk with Quorum Sensing Bacterial Sensors. Curr. Microbiol, 45, 250-254. https://doi.org/10.1007/s00284-002-3704-y

Dubensky, T. W., Liu, M. A., \& Ulmer, J. B. (2000). Delivery systems for gene-based vaccines. Mol. Med., 6(9), 723-732. https://doi.org/10.1007/BF03402189

Dubey, R. S.., \& Upadhyay, S. N. (2001). Microbial corrosion monitoring by an amperometric microbial biosensor developed using whole cell of Pseudomonas sp. Biosens Bioelectron, 16, 995-100. https://doi.org/10.1016/S0956-5663(01)00203-2 


\section{Mll Macrothink}

Journal of Biology and Life Science ISSN 2157-6076 2020, Vol. 11, No. 2

Gewirtz, A. M. (1999). Myb targeted therapeutics for the treatment of human malignancies. Oncogene, 18(19), 3056-3062. https://doi.org/10.1038/sj.onc.1202785

Ghattas, N. I., \& Carver, J. S. (2012). Integrating nanotechnology into school education: a review of the literature. Research in Science and Technological Education, 271-284. https://doi.org/10.1080/02635143.2012.732058

Hansen, L. H., \& Sorrensen, S. J. (2001). The Use of Whole-Cell Biosensors to Detect and Quantify Compounds or Conditions Affecting Biological Systems. Microb. Ecol., 42(4), 483-494. https://doi.org/10.1007/s00248-001-0025-9

Hulla, J. E., Sahu, S. C., \& Hayes, A. W. (2015). Nanotechnology: History and future. Human and Experimental Toxicology, 34(12), 1318-1321. https://doi.org/10.1177/0960327115603588

Kitova, A. E., Kuvichkina, T. N., Il'yasov, P. V., Arinbasarova, A. Y., \& Reshetilov, A. N. (2002). A reactor-type biosensor based on Rhodococcus erythropolis HL PM-1 cells for detecting 2,4-dinitrophenol. Appl Biochem Microbiol., 38, 500-505. https://doi.org/10.1023/A:1019989023130

Knight, C. G. (1981). Liposomes, from physical structure to therapeutic applications. Elsevier/North-Holland Biomedical Press; New York: sole distributors for the U.S.A. and Canada, Elsevier North-Holland, Amsterdam; New York (ISBN 0444803203).

Köhler, S., Belkin, S., \& Schmid, R. D. (2000). Reporter gene bioassays in environmental analysis. Fresenius J Anal Chem., 366(6-7), 769-779. https://doi.org/10.1007/s002160051571

Kwakye, S., \& Baeumner, A. (2003). A Microfluidic Biosensor Based on Nucleic Acid Sequence Recognition. Anal. Bioanal. Chem., 376(7), 1062-1068. https://doi.org/10.1007/s00216-003-2063-2

Lee, P. Y., \& Wong, K. K. (2011). Nanomedicine: a new frontier in cancer therapeutics. Curr Drug Deliv., 8, 245-253. https://doi.org/10.2174/156720111795256110

Lin, S. Y., Wu, M. T., Cho, Y. I., \& Hui-Huang, C. H. H. (2015). The effectiveness of a popular science promotion program on nanotechnology for elementary school students in I-Lan City. Research in Science and Technological Education, 22-37.

Loke, S. L., Stein, C. A., Zhang, X. H., Mori, K., Nakanishi, M., Subasinghe, C., et. al. (1989). Characterization of oligonucleotide transport into living cells. Proc Natl Acad Sci USA 86, 3474-3478. https://doi.org/10.1073/pnas.86.10.3474

Luger, S. M., O'Brien, S. G., Ratajczak, J., Ratajczak, M. Z., Mick, R., Stadtmauer, E. A. et. al. (2002). Oligodeoxynucleotide-mediated inhibition of c-myb gene expression in autografted bone marrow: a pilot study. Blood, 99(4), 1150-1158. https://doi.org/10.1182/blood.V99.4.1150

Mani, S., Rudin, C. M., Kunkel, K., Holmlund, J. T., Geary, R. S., Kindler, H. L. et. al. (2002) Phase I Clinical and Pharmacokinetic Study of Protein Kinase C- $\alpha$ Antisense Oligonucleotide ISIS 3521 Administered in Combination with 5-Fluorouracil and Leucovorin in Patients with 
Advanced Cancer. Clin. Cancer Res., 8, 1042-1048.

https://clincancerres.aacrjournals.org/content/8/4/1042

Marcucci, G., Byrd, J. C., Dai, G., Klisovic, M. I., Kourlas, P. J., Young, D. C. et.al. (2003). Phase 1 and pharmacodynamic studies of G3139, a Bcl-2 antisense oligonucleotide, in combination with chemotherapy in refractory or relapsed acute leukemia. Blood, 101(2), 425-432. https://doi.org/10.1182/blood-2002-06-1899

Misra, R., Acharya, S., \& Sahoo, S. K. (2010). Cancer nanotechnology: application of nanotechnology in cancer therapy. Drug Discov. Today, 15, 842-850. https://doi.org/10.1016/j.drudis.2010.08.006

Mitchell, R. J., \& Gu, M. B. (2003). An Escherichia coli biosensor capable of detecting both genotoxic and oxidative damage. Appl Microbiol Biotechnol., 64, 46-52. https://doi.org/10.1007/s00253-003-1418-0

Mohanty, S. P., \& Kougianos, E. (2006). Biosensors: A Tutorial Review. IEEE Potentials, 25(2), 35-40. https://doi.org/10.1109/MP.2006.1649009

Morris, M. J., Tong, W. P., Cordon-Cardo, C., Drobnjak, M., Kelly, W. K., Slovin, S. F. et al. (2002). Phase I trial of BCL-2 antisense oligonucleotide (G3139) administered by continuous intravenous infusion in patients with advanced cancer. Clin Cancer Res., 8, 679-683.

NBIC (2018).

https://statnano.com/news/65159/Nanotechnology-Patents-of-2018-at-the-USPTO-and-EPO-t hrough-the-Lens-of-Statistics.

Orive, G., Hernandez, R. M., Gascon, A. R., Calafiore, R., Chang, T. M. S., De Vos, P., et al. (2003). Cell encapsulation: Promise and progress. Nat. Med., 9, 104-107. https://doi.org/10.1038/nm0103-104

Pelleg, B., Figueroa, M., VanKouwenberg, M., Fontecchio, A., \& Fromm, E. (2011). Implementing nanotechnology education in the high school classroom. Frontiers in Education Conference (FIE), Rapid City, SD, pp. F4D-1-F4D-6. https://doi.org/10.1109/FIE.2011.6142886

Prow, T. W., Chen, X., Prow, N. A., Fernando, G. J. P., Tan, C. S. E., Raphael, A. P. et al. (2010). Nanopatch-targeted skin vaccination against West Nile Virus and Chikungunya virus in mice. Small, 6(16), 1776-1784. https://doi.org/10.1002/smll.201000331

Rudin, C. M., Holmlund, J., Flemming, G. F., Mani, S., Stadler, W. M., Schumm, P. et. al. (2001). Phase I trial of ISIS 5132, an antisense oligonucleotide inhibitor of c-raf-1, administered by 24-hour weekly infusion to patients with advanced cancer. Clin Cancer Res., 7, 1214-1220.

Salamanca-Buentello, F., Persad, D. L., Court, E. B., Martin, D. K., Daar, A., \& Singer, P. A. Nanotechnology and the Developing World (2005). PLoS Medicine, 2(5), e97. https://doi.org/10.1371/journal.pmed.0020097 
Scientific World Info. (2020). Applications of Nanotechnology in Electronics and Communication Engineering:

https://www.scientificworldinfo.com/2020/01/nanotechnology-inelectronics-and-communicat ion.html

South African Nanotechnology Initiative. (2014). https://www.sani.org.za

Thévenot, D. R., Toth, K., Durst, R. A., \& Wilson, G. S. (2001). Electrochemical Biosensors: Recommended Definitions and Classification. Biosens. Bioelectron. 16(1-2), 121-131. https://doi.org/10.1016/S0956-5663(01)00115-4

Ulmer, J. B., Sadoff, J. C., \& Liu, M. A. (1996). DNA vaccines. Curr. Opin. Immunol., 8(4), 531-536. https://doi.org/10.1016/S0952-7915(96)80042-2

UnderstandingNano.com (2019).

https://www.understandingnano.com/environmental-nanotechnology.html.

UnderstandingNano.com (2019). https://www.understandingnano.com/nanoparticles.html.

UnderstandingNano.com. (2019).

https://www.understandingnano.com/nanotechnology-energy.html.

Vo-Dinh, T., Cullum, B. M., \& Stokes, D. L. (2001). Nanosensors and biochips: frontiers in biomolecular diagnostics. Sensors and Actuators B: Chemical, 74(1-3), 2-11. https://doi.org/10.1016/S0925-4005(00)00705-X

Vo-Dinh, T., \& Cullum, B. (2000). Biosensors and Biochips: Advances in Biological and Medical Diagnostics. Fresenius' Journal of Analytical Chemistry, 366(6-7), 0540-0551. https://doi.org/10.1007/s002160051549

Waters, J. S., Webb, A., Cunningham, D., Clarke, P. A., Raynaud, F., Di Stefano, F., et al. (2000). Phase I clinical and pharmacokinetic study of bcl-2 antisense oligonucleotide therapy in patients with non-Hodgkin's lymphoma. $J$ Clin Oncol., 18, 1812-1823. https://doi.org/10.1200/JCO.2000.18.9.1812

Yakubov, L. A., Deeva, E. A., Zarytova, V. F., Ivanova, E. M., Ryte, A. S., Yurchenko, L. V., Vlassov, V. V. (1989). Mechanism of oligonucleotide uptake by cells: involvement of specific receptors? Proc Natl Acad Sci U S A., 86(17), 6454-6458.

https://doi.org/10.1073/pnas.86.17.6454

\section{Copyright Disclaimer}

Copyright for this article is retained by the author(s), with first publication rights granted to the journal.

This is an open-access article distributed under the terms and conditions of the Creative Commons Attribution license (http://creativecommons.org/licenses/by/4.0/). 